\title{
Infrastructural Organization of Geospatial Data in The Global Level: A Case Study of Albanian Global Mapping Dataset
}

\author{
Milot Lubishtani $^{1}$, Bashkim Idrizi ${ }^{2 *}$, Subija Izeiroski ${ }^{3}$, Fitore Bajrami Lubishtani ${ }^{2}$ \\ ${ }^{1}$ Department of Geodesy, Polytechnic University of Tirana, Tirana, 1001, Albania \\ ${ }^{2}$ Department of Geodesy, University of Prishtina "Hasan Prishtina", Prishtina , 10000, Kosovo \\ ${ }^{3}$ Subsidiary Struga, Geo-SEE Institute, Skopje, 1000, North Macedonia \\ *Corresponding Author : bashkim.idrizi@uni-pr.edu
}

Received 12 January 2020/ Revised 20 March 2020/ Accepted 17 April 2020/ Published 24 April 2020

\begin{abstract}
Today, the development of economic and financial situation concerning the protection of environment and natural resources in a wider scope depends on the use of geospatial data. One of the main aims of the infrastructural organization of geospatial data is to provide users to be capable of acquiring complete, exact and updated dataset at the right time. This is necessary for providing an ideal environment, where all stakeholders can work collaboratively in an effective way, in order to solve environmental issues and to achieve their targets. Global Mapping (GM), a project established by United Nations, is one of the crucial contributions to the development of Global Spatial Data Infrastructure (GSDI). This case study on Albanian GM dataset was aimed at performing analyses of infrastructural organization of geospatial data in global-intercontinental level. Data standardization of GM as contributor of GSDI was analyzed through developed Albanian GM dataset. The main components taken into consideration for performing research analyses were data and metadata, technology, institutional framework, policies, interoperability, network services, search opportunities, and data sharing within GSDI. The main findings of this study are the necessity of infrastructural organization of geospatial data in the global level, known as GSDI, by including official geospatial datasets developed by the national mapping organizations of countries all over the world, in order to be used for environmental monitoring and protection, as well as for early warning management in international level. Finally, based on the research results, four conclusions for GSDI are offered, in order to be considered as guideline for further development of unified and globally homogeneous infrastructure of spatial data set.
\end{abstract}

Keywords: GSDI; GM; spatial data infrastructure; Albania.

\section{Introduction}

According to Fereira (2005) recent technological advances in geospatial data collection, such as mobile phones, the Earth observation and GPS (Global Positioning 
System) satellites, have created massive data sets with better spatial and temporal resolution than ever. Space agencies worldwide planned to launch around 260 Earth observation satellites over the next 15 years. This novel scenario points to the need and spurs on motivation for creating new infrastructures and technologies in order to efficiently store, process, analyze and disseminate large amount of spatiotemporal datasets. According to Williamson et al. (2005), Cignetti et al. (2019), Hoffman-Hall (2019), Petel (2017), Specka (2019), Thapa et al. (2019) spatial data, also known as geospatial data or geographic information, are defined as data associated with a specific location on the earth, particularly information regarding natural phenomena, and cultural and human resources. Spatial data include maps, aerial and satellite images.

Many organizations from local, national and regional level produce geospatial data for different purposes. Nowadays, we face challenges concerning the production and use of geospatial data. Some of them are: (1) in most cases data are collected by different organizations and are often incompatible, (2) very often data are with poor quality and poor documentation, (3) organizations that produce spatial data are often restricted to distribute high quality spatial data.

The Spatial Data Infrastructure (SDI) concept is generally used to avoid gaps within spatial datasets and duplication in data production in addition to other well-known spatial data problems. According to Wu et al. (2018), Thompson \& de Beurs (2018), Yang et al. (2018), Forkel et al. (2017), Lu et al. (2017), Chen \& Wang (2017), Vasin \& Yasakov (2016) Creating efficient SDIs is an innovative way aiming to design an environment for collaboration and cooperation to solve environmental issues. SDI is mainly a collection of five components which are core spatial data, policies, standards, technologies and institutional arrangement that facilitate the access to geographically-related information (Park et al., 2016; Lee et al., 2015; Choi et al., 2019; Yu et al., 2016); Sinnott \& Voorsluys, 2016); Foster \& Mayfield, 2016). An efficient way of accessing Geospatial Information for public use is by developing geoportals. In fact, a geoportal within the framework of an SDI is a gateway for accessing spatial data, metadata, users and tools that are interactively linked with main aim to use geospatial data in a flexible and efficient way. At the other hand, the geoportals are not just tools but they also facilitate the searching procedures for spatial data.

Four key concepts underpinning all SDIs are: (1) The overriding objective of an SDI is to maximize the use of spatial information. This requires ready access to the geographic information assets held by a wide range of stakeholders in both public and private sector, (2) SDIs cannot be realized without coordinated action on the part of governments and agency 
partners, (3) SDIs must be user driven. Their primary purpose is to support decision making for many different purposes, and (4) SDI implementation involves a wide range of activities. These include not only technical matters such as data, technologies, standards, and delivery mechanisms, but also institutional matters related to organizational responsibilities and overall national information policies, as well as questions related to the availability of the financial and human resources needed for this task.

Concerning the organization of spatial data in the global level, there is an ongoing initiative called Global Spatial Data Infrastructure (GSDI). Currently GSDI is at an early stage of development, particularly after the establishment of GSDI Association in 2002 which includes the development of a proper organizational model, policy and framework, as well as the set up of different working groups for designing and conducting research on the other important components of GSDI. Within the framework of this initiative, regional organizations such as EUROGI and PCGIAP are playing an important role. This initiative was defined by the participants at the Second GSDI Conference (held at Chapel Hill, USA, in October 1997) as generally encompassing "the policies, organizational remits, data, technologies, standards, delivery mechanisms, and financial and human resources necessary to ensure that those working at the global and regional scale are not impeded in meeting their objectives".

As a result of the growing need for organization and access of geospatial data in many fields, organizations raised the need for development and implementation of spatial data infrastructures (SDI) as well as further researches related to theory and concepts of SDI. Hjelmager et al. (2008) state that an SDI is an evolving concept about facilitating and coordinating the exchange and sharing of spatial data between stakeholders from different levels in the spatial data community. One of the core characteristics of well-organized spatial data is the hierarchical structure. These structures can be found nearly everywhere in nature and the man-made environment, e.g. taxonomies, organizations, databases, political systems and government, and parent-child human relationships.

The properties of hierarchical systems include simplicity and complexity, upper and lower levels, as well as nested systems within the hierarchical structure. These properties have been adapted in some spatial data applications. In general, it can be said that the higher the level of the SDI, the lower the detail of the data.The hierarchy of SDI systems can be seen in a top down umbrella view (Figure 1), or a bottom up building block view (Rajabifard et al., 2000; Williamson et al., 2005). 


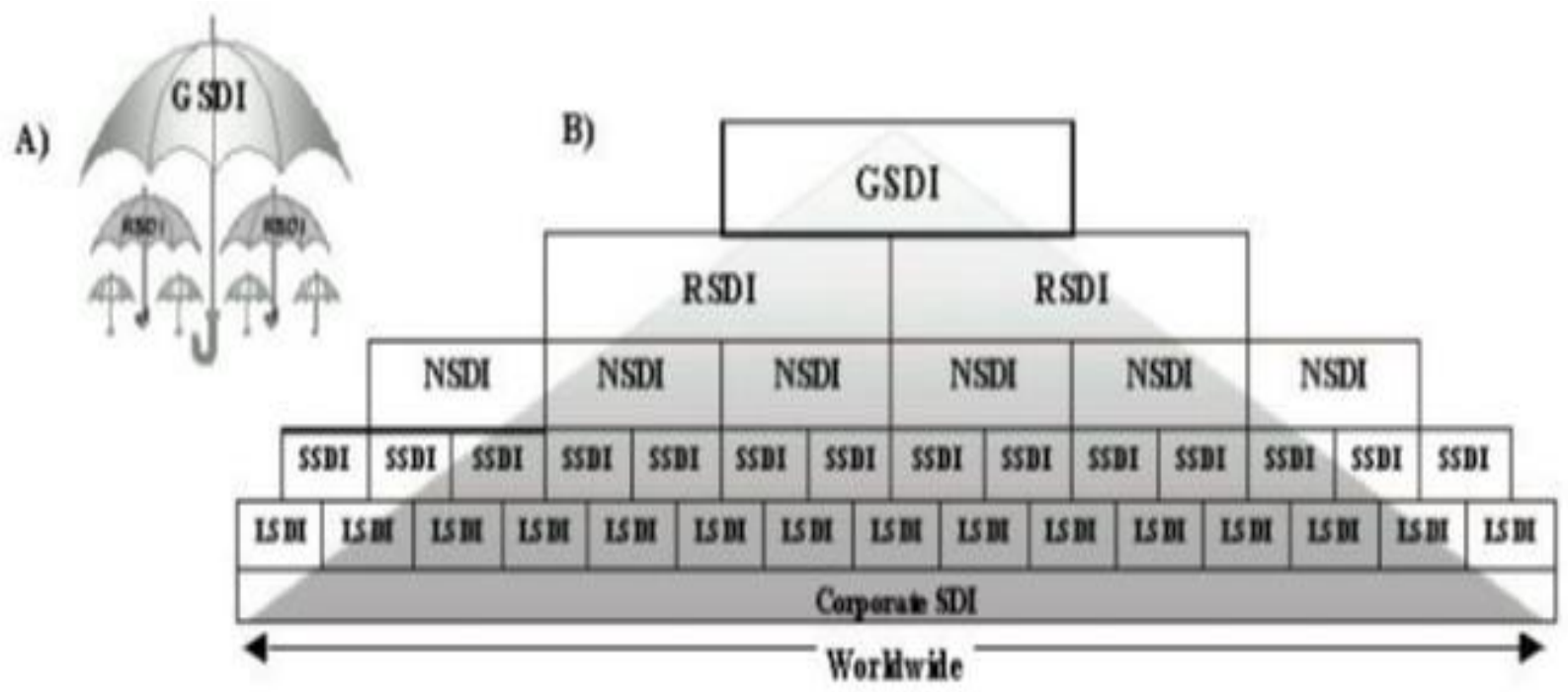

Figure 1. a)An Umbrella View of SDI

b) ABuilding Block View of SDI

The National Spatial Data Infrastructure is established in Albania by the law and consists in the National Geoportal by the State Authority for Geospatial Information (ASIG). Dataset resources for INSPIRE entries are data from Albanian Geographic (Military) Institute (AGMI), Albanian Geologic Survey (AGS), Agency for Legalization of Urban and Informal Zones and Buildings (ALUIZNI), Central Technical Archive in Tirana, Central Office Registration of Immovable Properties and Parcels and its branches, National Agency of Forest, National Agency of Water, National Agency of Environment, National Agency of Territory Administration, Urban Offices in Municipalities or Cities Hall in Albania, Private Companies.

In the Republic of Albania, the organization responsible for developing NSDI is the State Authority for Geospatial Information-ASIG. ASIG in collaboration with Norway Cadastre Authority Statens Kartverk have started initial activity to establish spatial data infrastructure in Albania in compliance with the European initiatives and trends. State Authority for Geospatial Information (ASIG) was established in 2013, according to Law $72 / 2012$ "On the organization and functioning of the national infrastructure of geospatial information in the Republic of Albania" (www.asig.gov.al). The establishment of the Ministry of Innovation, Information Technologies (MITIK) and Communication affirms and reinforces the government's determination for the implementation of national spatial data infrastructure (NSDI). In addition, ,the adoption of the INSPIRE Directive, the establishment of an institutional and legal frame for spatial data generation and distribution, and the provision of their use in a national level, are aimed to hinder all misunderstandings and 
duplication and improve the quality of the final projects deliverable especially for infrastructure studies and the environment.

The idea for developing the global map was launched as a result of unsuccessful completion of the IMW (International Map of the World in scale 1:1.000.000) and contemporary trends as a result of fast growing information technology in the last decade of the $20^{\text {th }}$ century for preparing the digital maps. Based on this idea, the global map has to replace the IMW with a new map in digital form according to the accepted homogeneous standards for entire globe. If we consider the structure of the global map,especially regarding the standards listed in its specifications, since its beginning till today,we can see that the global map is not designed as a standard map, but it merely represents the GIS database format with specifically defined standards. The lack of cartographic key (cartographic symbols), the lack of cartographic/graphic representation, and the absence of defined map projection are the main arguments which prove that global map is notactually a map but it is a GIS database, i.e. global map itself does not contain the basic elements that characterize a map (Idrizi et al., 2011). Global Map is a Digital Geographic Dataset covering the global land areain the scale of 1:1,000,000 and spatial resolution of about $1 \mathrm{~km}$. It is, easily accessible with marginal costs, currently freely downloadable for non-profit purposes.

This research case study on Albanian Global Map Dataset combines both, the theoretical and practical issues, conducted, by interaction of theoretical components within practical processes for developing GM dataset for one country and analyzing the necessity for infrastructural organization of geospatial data in the global level based on national level data, known as Global Spatial Data Infrastructure (GSDI). This research offers the answer to the main question on the importance of GSDI for international cooperation from national up to global level, on issues related to the environment and official early warning global spatial datasets. The study was performed by using the process of developing the Albanian Global Map dataset, as a case study, in which all research analyzes were conducted.

\section{Methods}

Derived from a literature research, according to Crompvoets (2006) the following SDI-components are to be considered as the main bricks of Spatial Data Infrastructures, i.e.: (1) Data Sources (organizations generating spatial data); (2) Users of spatial data (human resources), (3) Agreed set of rules, standards (technological and data definition), protocols,procedures, instructions, guidelines); (4) Policies (legislation (copyright), accessibility, finance) ; (5) Institutional framework (arrangements) affecting databases, meta- 
data policy,standards; (6) (Networked) Spatial-datasets (Fundamental datasets geodetic) positioning system, digital topographic frameworks, property register, administrative boundaries, elevation model), thematic datasets (soils, hydrology, land use), historical data, and Metadata); (7) Clearinghouse; (8) Legal and technical provision for universal connectivity among databases, directory information and legal rights to interconnect; Metadatabases and directories describing the content and components of databases; (9) The technologies facilitating the use and transfer of spatial data (Networks, Electronic Data Interchange, Open GIS, data handling facilities, data transfer media).

According to Idrizi (2018), the basic elements of an SDI are as follows: (1) Institutional framework, including legislation, organization, policies and practices; (2) Rules for financing and pricing and for handling of security, vulnerability and integrity; (3) Standards, including methods for describing spatial data, searching spatial data, ordering and transferring spatial data; (4) Fundamental spatial data sets, including geodetic frame, official digital map data, data on real properties, population, buildings and more; and (5) Technological framework including human and technical resources, meta data and catalogue services, information network, data distribution, services which makes it easy for users to search, order and collect spatial data.

Within a national framework of SDI, various datasets (sometimes also indicated by authentic datasets after they have gained a legal status) may be included, such as: (1) coordinate reference systems; (2) object catalogue including object definitions; (3) geographic name gazetteers; (4) cadastral data; (5) large scale topographic data; (6) elevation data; (7) administrative subdivisions; (8) transportation networks.

On the other side, a global framework of SDI may contain a combination of national core datasets or regional datasets. These spatial datasets should be determined a common reference system, object catalogue gazetteers for different types of data in order to be allowed combined use of the different datasets for different purposes. Data harmonization is an act of reconciling the definition and representation formats of data elements in a domain of interest. It entails a set of activities that improves the consistency in the use of data elements in terms of their meaning and representation format. In the process of data harmonization, a set of core data elements (data elements expressed using different vocabularies but with identical meaning) can be extracted. One of the main goals of data harmonization is to eliminate redundancies and duplication of datasets in the submission of international trade data. 
There are two general approaches for harmonizing data: input harmonization and output harmonization (Peter \& Emily, 2016): (1) Input harmonization aims to achieve standardized measurement processes and methods in all national or regional populations. Comparability can be realized through standardization of definitions, indicators, classifications, training, and technical requirements, (2) Output harmonization begins with different national or regional measurements, possibly derived from non-standardized measurement processes.

Interoperability is defined as the ability of information and communication technology (ICT) systems and of the business processes they support to exchange data and to enable the sharing of information and knowledge (European Commission, 2004). The State Authority for Geospatial Information (ASIG) of Albania, following a successful cooperation, signed on $26^{\text {th }}$ of April 2018, the institutional cooperation agreement with Statens Kartverk for the implementation of the project was financed by the Government of Norway for the Western Balkan countries with the object: "Capacity Building of the State Authority for Geospatial Information on Providing Geographic Information to Users". The objectives of this agreement are: (1) Enhancing the capacity of the State Authority for Geospatial Information to provide geographic information to users, (2) Developing the plan and the first version of the integrated information system for coastal areas with testing in an are, (3) Developing the curricula in mapping and cadaster in university system.

The establishment of the National Geoportal is in its initial phase of structuring and, performing a harmonization of geospatial data in order for users to find it as complete, accurate and up to date. For the users concerned about these geospatial information (citizens, scholars, etc..), ASIG suggests that the data obtained from the Geoportal, firstly have to be verified and confirmed in the relevant institutions, in order that they may gainthe most accurate final information.

The vector data of Global Map V1/V2 (national and regional version) can be downloaded in VPF (Vector Product Format), SHAPE and GML (Geography Markup Language) formats. VPF is a standard format, structure, and organization for large geographic databases that are based on a geo-relational data model, combinatorial topology and set theory, and are intended for direct use (Idrizi, 2017). Because the use of VPF files is so limited by the existing GIS software's, on October $10^{\text {th }} 2008$ the existing GM vector data (national/regional version) has also been published in SHAPE format, which is simpler and more user-friendly format. 
On October $25^{\text {th }} 2009$, the GML (standardized in ISO 19136) format has replaced the former VPF as the official distribution format of GM data, which provides a standard format for transferring digital geographic data (Idrizi et al., 2011). The Global Map product will encompass the entire globe, at a scale of 1:1 million. All the data sets will be consistent with this scale and these specifications (Global Map Specifications Version 2.2., 2012). On the other side, a global framework of SDI may contain a combination of national core datasets or regional datasets. These spatial datasets should be determined a common reference system, object catalogue gazetteers for different types of data in order to be allowed combined use of the different datasets for different purposes.

Data harmonization is an act of reconciling the definition and representation formats of data elements in a domain of interest. It entails a set of activities that improves the consistency in the use of data elements in terms of their meaning and representation format. In the process of data harmonization, a set of core data elements (data elements expressed using different vocabularies but with identical meaning)can be extracted.One of the main goals of data harmonization is to eliminate redundancies and duplication of datasets in the submission of international trade data. There are two general approaches for harmonizing data: input harmonization and output harmonization (Peter \& Emily, 2016): (1) Input harmonization aims to achieve standardized measurement processes and methods in all national or regional populations. Comparability can be realized through standardization of definitions, indicators, classifications, training, and technical requirements, (2) Output harmonization begins with different national or regional measurements, possibly derived from non-standardized measurement processes.

Interoperability is defined as the ability of information and communication technology (ICT) systems and of the business processes they support to exchange data and to enable the sharing of information and knowledge (European Commission, 2004). The State Authority for Geospatial Information (ASIG) of Albania, following a successful cooperation, signed on 26 th of April 2018, the institutional cooperation agreement with Statens Kartverk for the implementation of the project was financed by the Government of Norway for the Western Balkan countries with the object: "Capacity Building of the State Authority for Geospatial Information on Providing Geographic Information to Users". The objectives of this agreement are: (1) Enhancing the capacity of the State Authority for Geospatial Information to provide geographic information to users, (2) Developing the plan and the first version of the integrated information system for coastal areas with testing in an area, (3) Developing the curricula in mapping and cadaster in university system. 
The establishment of the National Geoportal is in its initial phase of structuring and, performing a harmonization of geospatial data in order for users to find it as complete, accurate and up to date. For the users concerned about these geospatial information (citizens, scholars, etc..), ASIG suggests that the data obtained from the Geoportal, firstly have to be verified and confirmed in the relevant institutions, in order that they may gainthe most accurate final information.

The vector data of Global Map V1/V2 (national and regional version) can be downloaded in VPF (Vector Product Format), SHAPE and GML (Geography Markup Language) formats. VPF is a standard format, structure, and organization for large geographic databases that are based on a geo-relational data model, combinatorial topology and set theory, and are intended for direct use (Idrizi, 2017). Because the use of VPF files is so limited by the existing GIS software's, on October $10^{\text {th }} 2008$ the existing GM vector data (national/regional version) has also been published in SHAPE format, which is simpler and more user-friendly format.

On October $25^{\text {th }} 2009$, the GML (standardized in ISO19136) format has replaced the former VPF as the official distribution format of GM data, which provides a standard format for transferring digital geographic data (Idrizi et al., 2011). The Global Map product will encompass the entire globe, at a scale of 1:1 million. All the data sets will be consistent with this scale and these specifications (Global Map Specifications Version 2.2., 2012).

\section{Results and Discussion}

The Republic of Albania has participated in global mapping project since $30^{\text {th }}$ June 2016 in Level B, through State Authority for Geospatial Information (ASIG) as national mapping and spatial data infrastructure organization. Republic of Albania was the last country participating in GM project, before the dissolution of ISCGM and the termination of the Global Mapping Project on August 2016.

Albanian Global Map V2, consists both, the vector and raster layers, 8 layers in total, released on $14^{\text {th }}$ of July 2016 in www.iscgm.org, as freely downloadable for non-commercial use (Lubishtani \& Idrizi, 2016). Official data wereretrieved from governmental institutions in charge of supplying the current and updated data sets as follows: (1) State Authority for Geospatial Information (ASIG), (2) Institute of transportation, (3) Albanian Institute of Statistics (INSTAT), (4) Military Geographical Institute of Albania, (5) Ministry of the Urban Development. In order to harmonize the input data with the GM V2.2 specification, all data received converted, harmonized and generalized, as well reprocessed in cases of satellite 
Milot Lubishtani et al / GEOSI Vol 5 No 1 (2020) 106-126

images. The next table and figure,present the list of the developed layers and the directory structure of Albanian GM dataset according to GM V2.2 specification for national/regional version.

Table 1. Global Map V1/V2 dataset layers - national/regional version

\begin{tabular}{ll}
\hline Vector Layers & Raster Layers \\
\hline Boundaries & Land Cover \\
Drainage & Land Use \\
Trasportation & Elevation \\
Population Centers & Vegetation \\
\hline
\end{tabular}

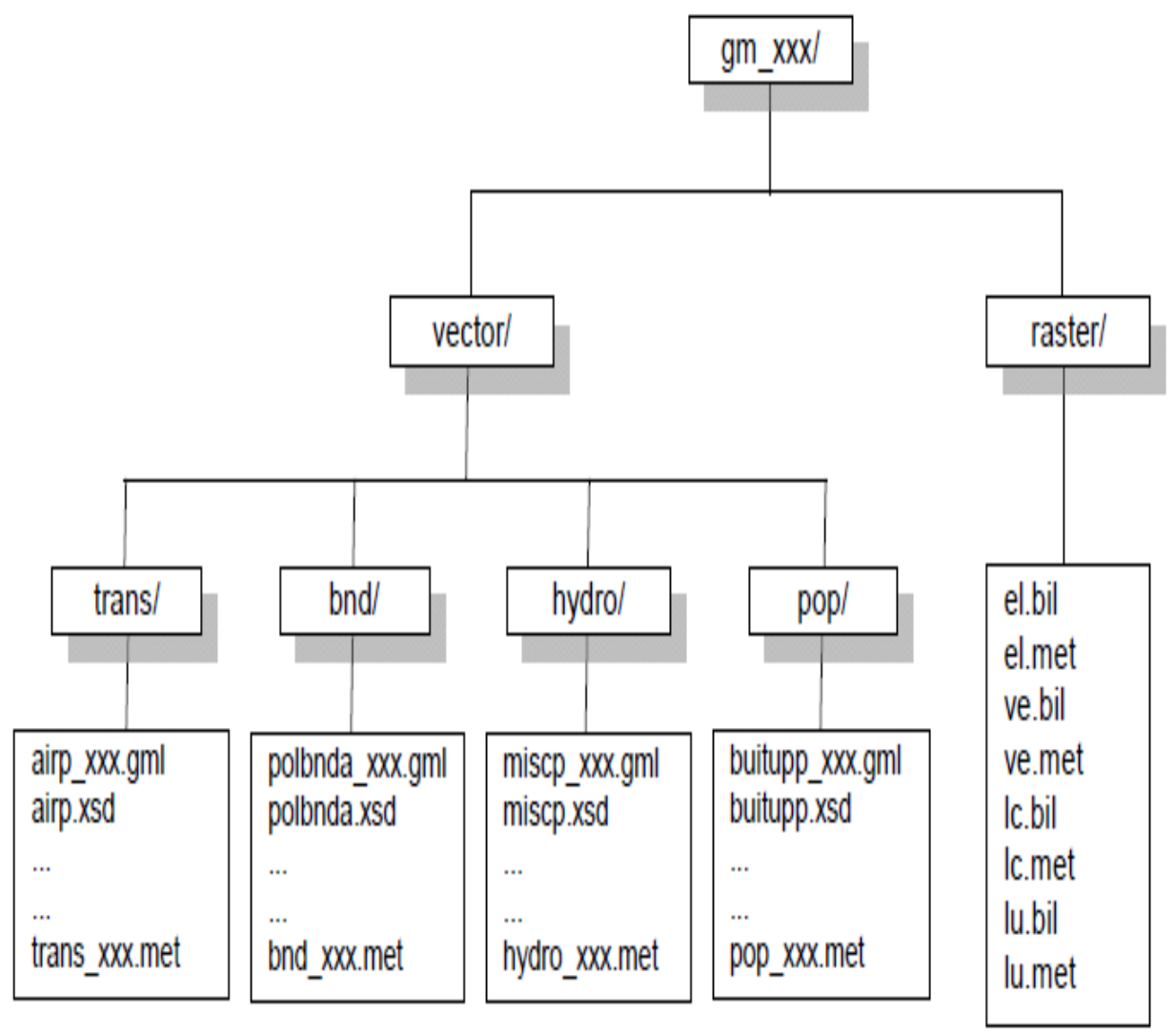

Figure 2. GM Directory Structure (Global Map Specifications Version 2.2)

As an output of the developed Albanian GM dataset, eight maps have been compiled, as follows (Lubishati \& Idrizi 2016; Lubishtani et al., 2018): 

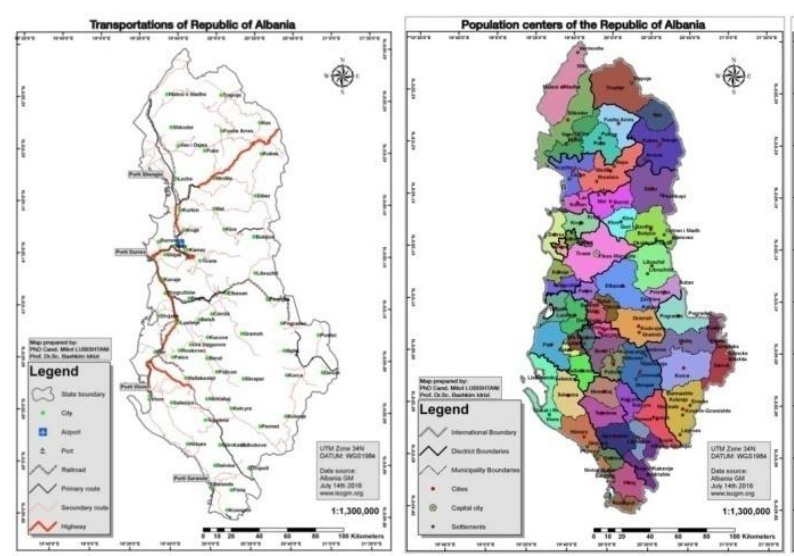

Figure 3.

Figure 4.

Figure 5.

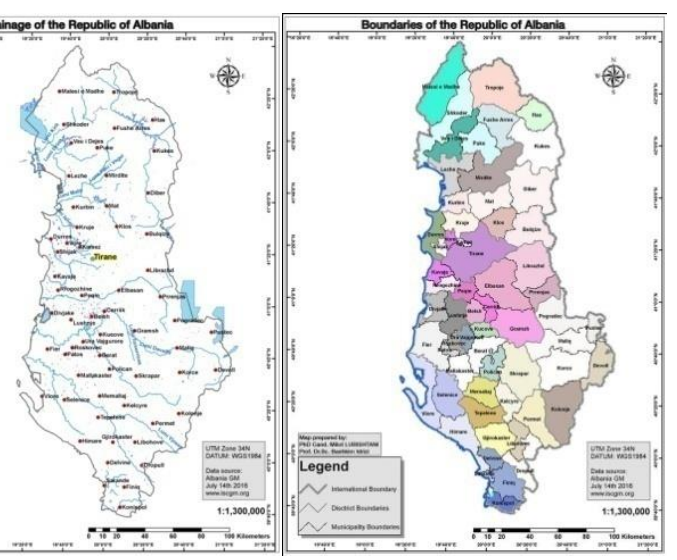

Transportation layer

Population centers layer

Drainage layer

Figure 6.

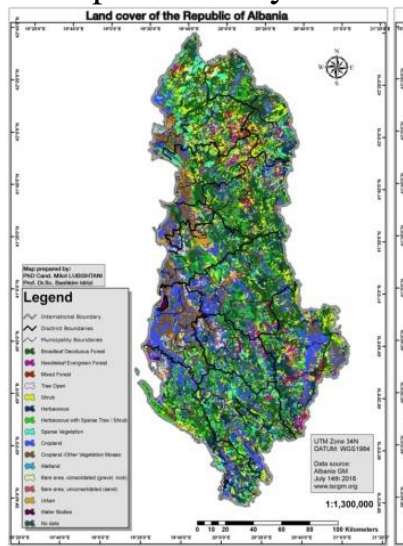

Figure 7.
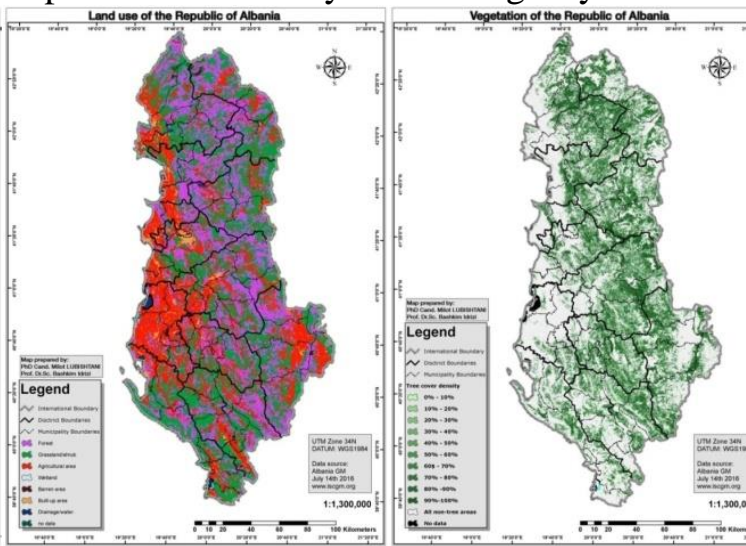

Boundaries layer

Land Cover layer

Figure 8.

Land Use layer
Figure 9.

Vegetation layer
Figure 10.

Elevation layer

From September 2016, based on the letter of approval from ASIG, the Albanian GM data set were migrated to the United Nations Geospatial Information Section (UNGIS), due to decision for transfer of GM data to UNGIS database, which has been formalized on August 2016, in New York, during the final $\left(23^{\text {rd }}\right)$ meeting of ISCGM (Lubishtani \& Idrizi, 2016).

Everything is happening somewhere; hence, most information is related to a place. This is the field, where Geographic Information System (GIS) comes in. A geographic information system has been described in several ways during its development and emergence as a technology. One can define GIS as a system of hardware and software, procedures and people designed to capture, to store, to manipulate, to analyze, and to display geo-referenced information (Longley et al., 2005).

SDI interconnects GIS-based servers across the internet. As stated by Groot \& Mc Laughlin (2000), an SDI encompasses first the networked geospatial databases and data handling facilities, and then other components. This leads to an argument that GIS can be considered the SDI block. Although the core SDI concept nests within its scope either base data collection activities or myriad applications built upon it, the infrastructure provides an 
ideal environment to connect applications to data influencing both data collection and applications construction through minimal appropriate standards and policies. The role of GIS within an SDI is vital. It first creates, manages and serves spatial information, then plays the same role for metadata, and finally provides access to users. Briefly we can consider GIS an underpinning technology for SDI. The notion that GIS is considered a block of an SDI can be seen in Figure 11.
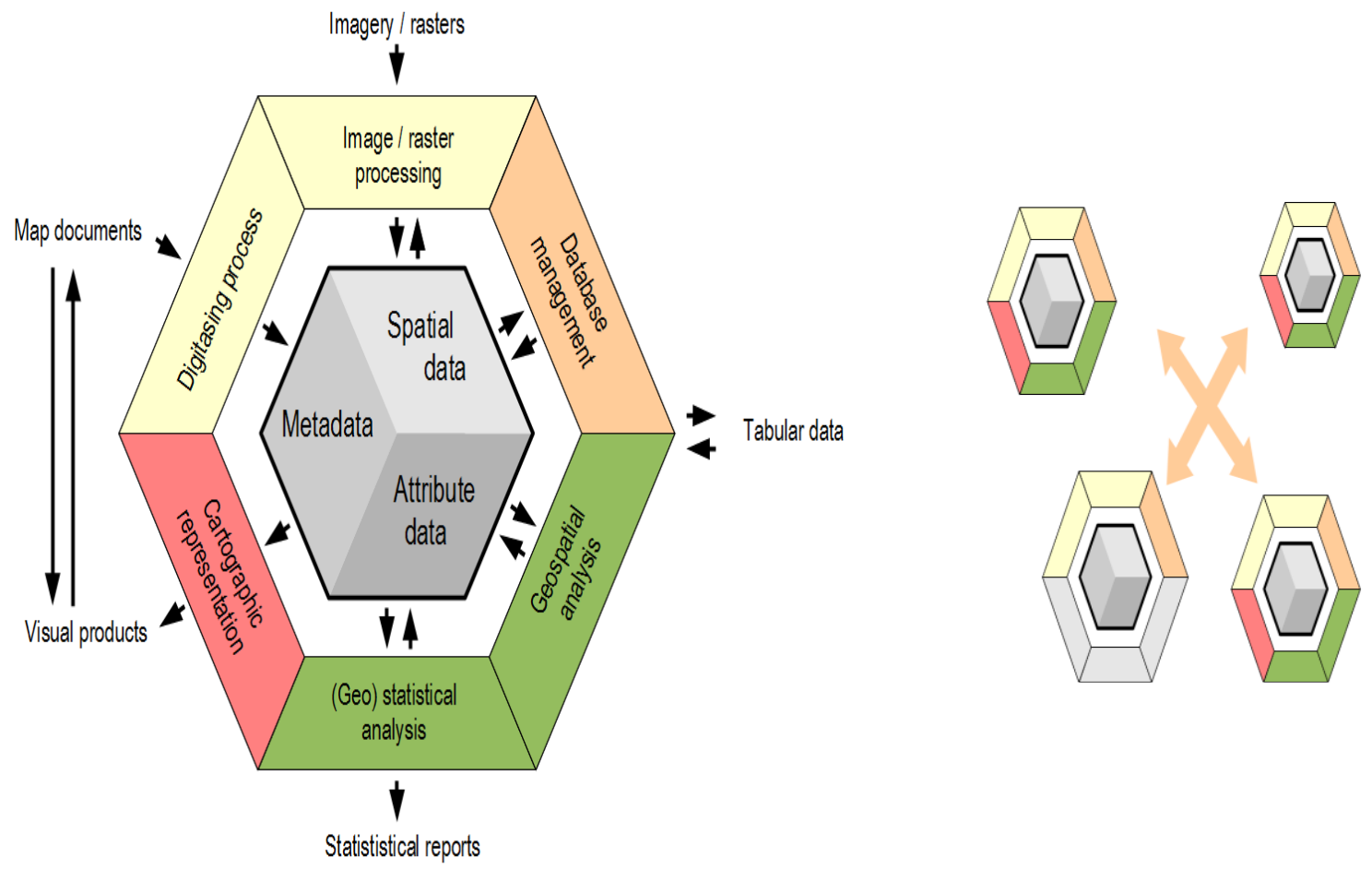

Figure 11. GIS as a block of Spatial Data Infrastructure

One of the main goals of the development of SDIs is to manage and more efficiently use the spatial data assets by considering the needs and information flows from the local level, up through state, national and regional levels and finally to the global (GSDI) level. Some of the essential properties of a hierarchical structure relevant for the understanding of hierarchies in general, and spatial hierarchies in particular are as follows: (1) Part-Whole property: Where an element on the higher level consists of one or more elements on the lower level, in view of a part-whole relationship, the higher level is a whole and the lower element is its part, (2) Janus-Effect: An element at a hierarchical level has two different faces, one looking toward wholes in the higher level and the other looking toward 
parts in the lower level. This property was introduced as a fundamental property of all types of hierarchy, (3) Near Decomposability Property: The third fundamental property of hierarchy is called near decomposability. It is related to the nesting of systems within larger sub-systems, and is based on the fact that interactions between various kinds of systems decrease in strength with distance. Components that are closer to each other interact more strongly than components that are far apart, many of them are at the same level. Figure 12 summarizes the common functional user requirements associated with the relevant steps in the resource life cycle (Díaz et al., 2011). Moving clockwise, resources must first be published in the SDI, so that they are available for the other stakeholders. Then, these resources need to be made searchable and discoverable in the distributed system.

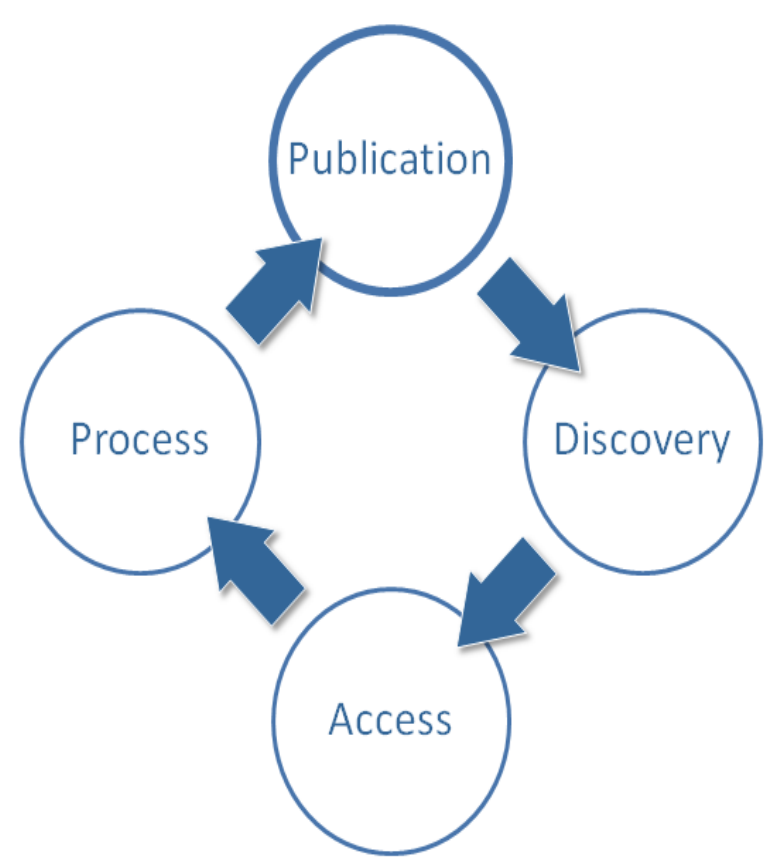

Figure 12. SDI Resource Life Cycle

As stated in Idrizi (2017) the main reasons and needs for standardization of spatial data are as follows: (1) Standardization lets peers communicate, (2) Minimizes cost of uptake of new information, (3) Maximizes utility and stability of information products, (4) Permits more applications to operate under known conditions. Mainly the following standardization organizations are in relation with SDI's : (1) International Organisation of Standardization (ISO TC 211, TC 204, JTC-1), (2) Inspire, (3) World Wide Web Consortium (W3C), OpenGIS Consortium (OGC), WSI-I (Web Services Interoperability organization), GSDI (Global Spatial Data Infrastructure), National Standards Organizations. According to 
Nebert (2009), many standardization activities exist with different roles and responsibilities that are relevant to implementing SDIs (figure 13).

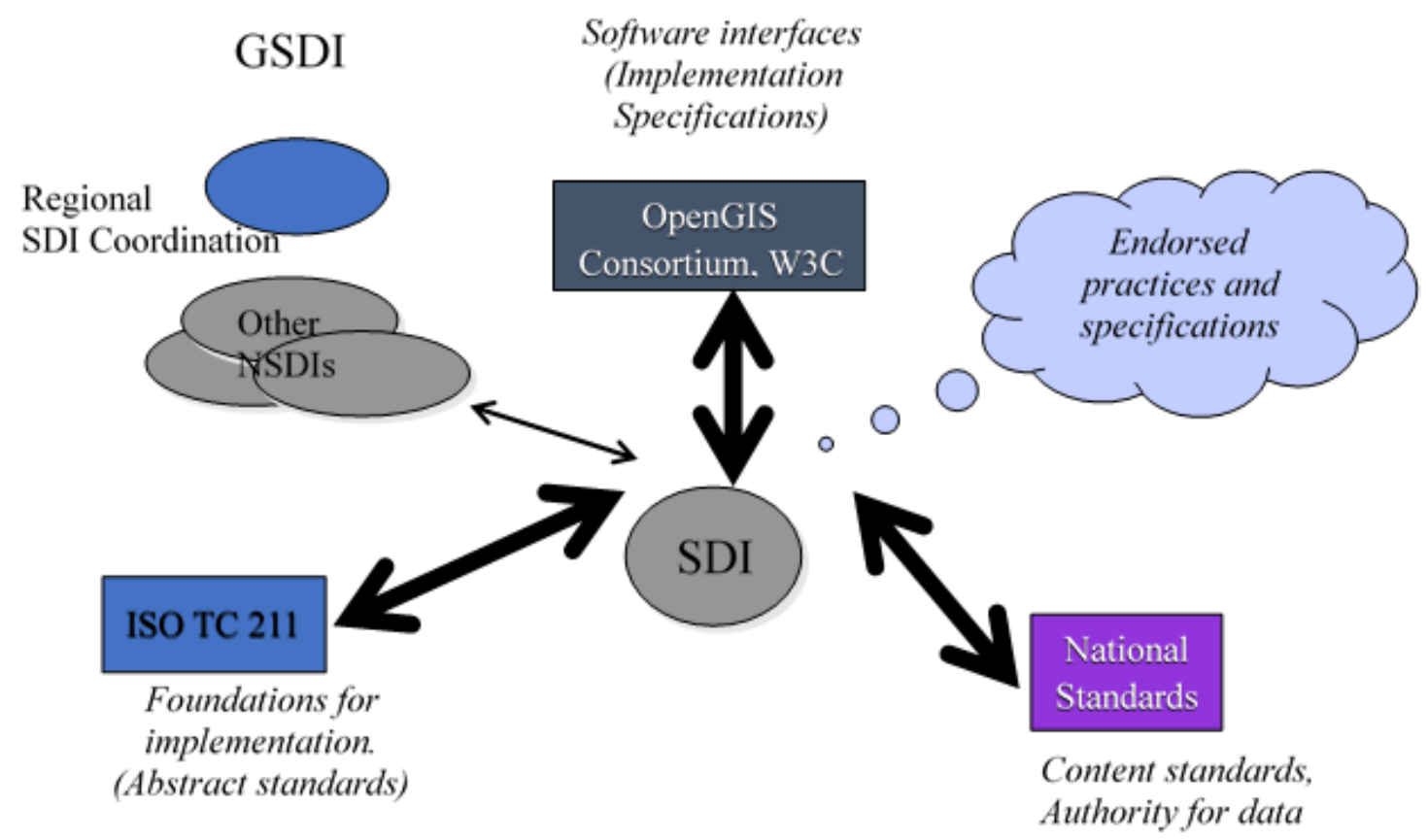

Figure 13. Geospatial Standardization in SDI (Nebert, 2009)

As can be seen in Figure 13 there are close interactions between SDI as a platform and standardization organizations like: OGC, W3C, ISO TC 211 as well as with other NSDI's. Some of the main benefits of data harmonization are: (1) provides a common basis for standardizing data for import, export and logistics information, (2) reduces data redundancy, data duplication and costs of data exchange, (3) ensures data compatibility and enables data interoperability among stakeholders, resulting in further facilitation of trade procedures, (4) provides common semantic standards for import, export and logistics information, (5) provides preparation to develop electronic trade documents, (6) supports the establishment of Single Window facilities: a single-entry point of standardized information and reuse of information to fulfill all import, export and transit related regulatory requirements.

As previously mentioned, the interoperability is the capability to communicate, execute programs, or transfer data among various functional units in a manner that requires the user to have little or no knowledge of the unique characteristics of those units (ISO 23821, 1993). There are four types of levels that obstruct interoperability of spatial data, i.e.: 
cross-border matching of datasets, cross-sector combinations of datasets from different sectors and different content, cross-type of data e.g. combining raster with vector data, and overlap where the same objects coming from different sources contradict both in value and in representation.

The Global Mapping Project is an effort in which National Mapping Organizations (NMOs) from more than 180 countries and regions of the world develop Global Map (GM) through international cooperation (Maruyama et al., 2005). The objectives of the Global Map project are to contribute to solving global environmental problems and achieving sustainable development. In its core meaning, Global Mapping is a digital geographic dataset of the whole globe which consists of eight thematic layers: boundaries, drainage, population centers, transportation, elevation, land use, land cover and vegetation. These thematic layers of GM dataset should be updated every five years. Some of the primary aims of the GM project are:

- $\quad$ Monitoring and early warning systems for natural disasters;

- Monitoring and management of natural resources;

- $\quad$ Assessment of the trends of environmental changes;

- Local, national and multinational physical development planning; and

- $\quad$ Informed decision-making of policy makers with a strategic database.

According to Idrizi (2006), despite the fact thatthe maps are prepared in local/national standards, GM dataset will enable all data of the Earth to be:

- in one place,

- with the same attributes,

- $\quad$ in the same format,

- in the same coordinate system,

- $\quad$ in the same scale, and

- with similar accuracy.

All structure of data in GM dataset is based on the international ISO standards for geographic data, i.e. ISO/TC 211The development of Global Map utilises these following six core ISO standards:

- $\quad$ ISO19136 for the data in GML format,

- $\quad$ ISO 3166 for nation codes, 
- $\quad$ ISO 19115 of metadata of GM-V2 by using ISO 19139 for encoding,

- $\quad$ ISO 15046 standard of metadata of V1,

- $\quad$ ISO 639 for language code,

- $\quad$ ISO 8601 for date code.

Some of the main objectives of ASIG during the process of building NSDI are:

- Creating geodetic framework to European standards to enable the support of a unique map of the entire territory of the Republic of Albania.

- Establishing national infrastructure geospatial data in the Republic of Albania, through Geoportal where everyone can access to geospatial data that possesses Albanian state.

- Designing and developing geo-information standards and their implementation in institutions, whether manufacturer or the geo Update.

Having a Global Map dataset in digital form on disposal principally allows the modeling of real life situations and also performance of various data manipulation and spatial data analyses. In practical solving issues concerning Global Map dataset may have limited uses at national and local scales. However, Global Map dataset is needed to address global, regional, and trans-boundary and in many cases national concerns and environmental issues. Therefore, the Albanian GM dataset as the latest updated data set will support all types of spatial analyses. By including Albanian GM dataset in the Global Map, direct contribution on regional environmental analyses will be enabled (Lubishtani \& Idrizi, 2016).

The concept of knowledge graph may be applied and integrated to SDIs to construct knowledge bases that link the geospatial entities and concepts contained in the data. Machine learning and data mining methods, such as latent semantic analysis and labeled latent Dirichlet allocation may help automatic inference and generation of high quality metadata from the content of maps and services (Li et al., 2015). According to $\mathrm{Hu} \& \mathrm{Li}$ (2017) SDIs heavily rely on computer and information technologies, and are continuously evolving with the technological advancements. Techniques commonly used in today's SDIs, such as Asynchronous JavaScript and XML (AJAX), enable asynchronous processing to speed up search performance as well as user experience. The strategy for building NSDI in Albania will lead to relation of NSDI through following strategic areas: (1) Cooperation Infrastructure, (2) Spatial data and services, (3) Standardization, (4) Legal framework, (5) Geodetic reference system, (6) Financing and pricing, (7) Research, development and 
education. In this way the generation of an important infrastructure is delivered in the national level such as ALBPOS, Orthophoto for Albania, increasing the level of spatial data within a global GIS. In this context the MITIK focuses on the implementation of the INSPIRE Directive which is considered not only a precondition for the integration of Albania in EU, but also the main base to establish the National Policies on EU. The following are some of the potential applications of Global Map datasets, i.e. developed Albanian Global Map dataset:

- Monitoring and early warning systems for natural disasters;

- Monitoring and management of natural resources;

- Assessment of the trends of global environmental changes;

- $\quad$ Local, national and multinational physical development planning;

- Informed decision-making of policy makers with a strategic database;

- Global/Regional/National perspective and contextual information;

- Developing ecosystem, drainage basins framework for environmental assessment;

- Quantifying trans boundary issues;

- $\quad$ Rapid Response capability;

- $\quad$ Environmental priority setting, analytical studies over large areas.

\section{Conclusion}

On the basis of the previous text we can see that there are some important similarities between Global Map and GSDI. The similarities are the global scope of GM and GSDI, their focus on geospatial data and ability to facilitate geospatial analysis and collaboration. This collaboration in some way is slightly different, because it emphasizes on a specific physical data product rather than spatial infrastructure development. The SDI development can be considered an important synergistic activity with Global Map project. Therefore, the international collaboration provides a number of relevant lessons and experiences for GSDI collaboration. It is also important to note that the Global Map project has only been in operation for about five years. Therefore, the organization may not have much operational history, but it can still offer some insights for GSDI. First of all, GSDI should focus on specific projects because such projects can help engage participants and educate them about 
the importance of SDI activities, such as the importance of metadata and collaboration between participants. With focus and participation in the development of specific spatial data product within Global Map activities, many countries can be assisted to recognize the importance of GSDI activities and usage. Second, the GSDI should develop partnerships and define relationships with other relevant regional and international activities. With defined and developed partnerships with these organizations, GSDI may have access to leveraged resources, increased visibility, and membership. As an example, the provision of an official invitation letter by UN to NMO's to participate in Global Map project may strengthenth a credibility of the activity and was instrumental in motivating countries' participation. Such partnerships can provide synergy and benefits for all the partners. For example, the partnership with PCGIAP and PCIDEA helps increase Global Map data development and also helps these organizations develop their regional collaborations.Third, GSDI needs to develop special activities in order to help developing countries to participate in the international collaborations since they often do not have the resources to participate in such activities. An important mechanism for such outreach is to facilitate country-to-country technical aid and support, such as the Level C and Level A membership categories in the Global Map project. Special grants and assistance programs are also helpful in this regard, such as the Japan International Cooperation Agency training classes and the ESRI grant program. Fourth, GSDI should also promote and emphasize the benefits of GSDI participation which is essential to increase the active participation in the organization. Global Map is currently working to distribute such messages to its members to increase active participation in Global Map project.

\section{Conflict of Interest}

The authors declare that there is no conflict of interest with any financial, personal, or other relationships with other people or organizations related to the material discussed in the article.

\section{References}

Chen, K., \& Wang, M. (2017). Local whittle likelihood estimators and tests for spatial lattice data. Journal of Statistical Planning and Inference, 191, 25-42. doi:10.1016/j.jspi.2017.06.001

Choi, W. -., Ahn, J. -., \& Shin, D. -. (2019). Study on the development of geo-spatial big data service system based on 7V in korea. KSCE Journal of Civil Engineering, 23(1), 388399. doi:10.1007/s12205-018-1764-1 
Cignetti, M., Guenzi, D., Ardizzone, F., Allasia, P., \& Giordan, D. (2019). An open-source web platform to share multisource, multisensor geospatial data and measurements of ground deformation in mountain areas. ISPRS International Journal of GeoInformation, 9(1) doi:10.3390/ijgi9010004

Crompvoets, J. W. H. C. (2006). National spatial data clearinghouses: worldwide development and impact : Wageningen University.

Díaz, L., \& Schade, S. (2011). GEOSS service factory: Assisted publication of geospatial content. In Advancing Geoinformation Science for a Changing World (pp. 423-442). Springer, Berlin, Heidelberg.

European Commission, (2004) European Interoperability Framework for Pan-European eGovernment services (vers. 1), European Communities.

Ferreira, K. R., de Queiroz, G. R., Vinhas, L., Câmara, G., Maurano, L. E., Souza, R. C. M., \& Sanchez, A. (2015). Towards a Spatial Data Infrastructure for Big Spatiotemporal Data Sets. In 17th Brazilian Symposium on Remote Sensing (SBSR), 2015. Proceedings (pp. 7588-7594).

Forkel, M., Dorigo, W., Lasslop, G., Teubner, I., Chuvieco, E., \& Thonicke, K. (2017). A data-driven approach to identify controls on global fire activity from satellite and climate observations (SOFIA V1). Geoscientific Model Development, 10(12), 44434476. doi:10.5194/gmd-10-4443-2017

Foster, D., \& Mayfield, C. (2016). Geospatial resource integration in support of homeland defense and security. International Journal of Applied Geospatial Research, 7(4), 53 63. doi:10.4018/IJAGR.2016100105

Groot, R., \& McLaughlin, J. (2000). Geospatial Data Infrastructure: concepts, cases and good practice. Oxford University Press.

Hjelmager, J., Moellering, H., Cooper, A., Delgado, T., Rajabifard, A., Rapant, P., ... \& Iwaniak, A. (2008). An initial formal model for spatial data infrastructures. International Journal of Geographical Information Science, 22(11-12), 1295-1309.

Hoffman-Hall, A., Loboda, T. V., Hall, J. V., Carroll, M. L., \& Chen, D. (2019). Mapping remote rural settlements at $30 \mathrm{~m}$ spatial resolution using geospatial data-fusion. Remote Sensing of Environment, 233 doi:10.1016/j.rse.2019.111386

Holland, P., (2003). Global, regional and national SDI initiatives and the Global Disaster Information Network (GDIN). Australian Surveying and Land Information Group.

Hu, Y. \& Li, W. (2017). "Spatial Data Infrastructures", The Geographic Information Science \& Technology Body of Knowledge, John P. Wilson (ed.).

Idrizi B. (2017). Presentation: SDI from local up to global level, Struga : Macedonia.

Idrizi, B. (2006). Developing of globally homogeneous geographic data set through global mapping project. Kartografija i geoinformacije (Cartography and Geoinformation), 5(6), 90-101.

Idrizi, B. (2018). General Conditions of Spatial Data Infrastructure. International Journal on Natural and Engineering Sciences, 12 (1): 57-62 
Idrizi, B., Meha, M., Nikolli, P., \& Kabashi, I. (2011). Data quality of Global Map and some possibilities/limitations for its wide utilisation for global issues. Survey Review, 44(325), 134-140.

Lee, M. H., Park, J. M., Shin, D. B., \& Ahn, J. W. (2015). A study on the selection of core services for geo-spatial big data. Journal of the Korean Society of Surveying, Geodesy, Photogrammetry and Cartography, 33(5), 385-396. doi:10.7848/ksgpc.2015.33.5.385

Li, W., Bhatia, V., \& Cao, K. (2015). Intelligent polar cyberinfrastructure: enabling semantic search in geospatial metadata catalogue to support polar data discovery. Earth Science Informatics, 8(1), 111-123.

Longley, P. A., Goodchild, M. F., Maguire, D. J., \& Rhind, D. W. (2005). Geographic information systems and science. John Wiley \& Sons.

Lu, Q., Ma, Y., \& Xia, G. -. (2017). Active learning for training sample selection in remote sensing image classification using spatial information. Remote Sensing Letters, 8(12), 1210-1219. doi:10.1080/2150704X.2017.1375610

Lubishtani M., Idrizi B. (2016). Developing of the Albanian Global Map dataset. Micro Macro Mezzo Geo Information, 7.

Lubishtani M., Idrizi B., Bajrami Lubishtani F. (2018). The historical development of Global Mapping. Proceedings, $1^{\text {st }}$ Western Balkan Conference on GIS, mine surveying, geodesy and geomatics. Tirana. Albania. ISBN: 978-9928-07-599-4.

Maruyama H., Sasaki H., and Takaki O., (2005). Global mapping project by national mapping organizations on the globe. In GSDI-9 Conference proceedings.

Nebert, D. (2009). "Introduction to Geospatial Web Services." Workshop presentation at Global Geospatial Conference (GSDI11)

Park, J. M., Yu, S. C., Ahn, J. W., \& Shin, D. B. (2016). A study on policy and system improvement plan of geo-spatial big data services in korea. Journal of the Korean Society of Surveying, Geodesy, Photogrammetry and Cartography, 34(6), 579-589. doi:10.7848/ksgpc.2016.34.6.579

Patel, N. N., Stevens, F. R., Huang, Z., Gaughan, A. E., Elyazar, I., \& Tatem, A. J. (2017). Improving large area population mapping using geotweet densities. Transactions in GIS, 21(2), 317-331. doi:10.1111/tgis.12214

Rajabifard A., Williamson I. P., Holland P. \& Johnstone G., (2000), From Local to Global SDI Initiatives: A Pyramid Building Blocks. Proceedings of the 4th GSDI Conference (13 - 15 March), Cape Town, South Africa.

Sinnott, R. O., \& Voorsluys, W. (2016). A scalable cloud-based system for data-intensive spatial analysis. International Journal on Software Tools for Technology Transfer, 18(6), 587-605. doi:10.1007/s10009-015-0398-6

Specka, X., Gärtner, P., Hoffmann, C., Svoboda, N., Stecker, M., Einspanier, U., . . . Heinrich, U. (2019). The BonaRes metadata schema for geospatial soil-agricultural research data - merging INSPIRE and DataCite metadata schemes. Computers and Geosciences, 132, 33-41. doi:10.1016/j.cageo.2019.07.005 
Thapa, R. B., Matin, M. A., \& Bajracharya, B. (2019). Capacity building approach and application: Utilization of earth observation data and geospatial information technology in the hindu kush himalaya. Frontiers in Environmental Science, 7 doi:10.3389/fenvs.2019.00165

Thompson, E. S., \& de Beurs, K. M. (2018). Tracking the removal of buildings in rust belt cities with open-source geospatial data. International Journal of Applied Earth Observation and Geoinformation, 73, 471-481. doi:10.1016/j.jag.2018.07.007

Vasin, Y. G., \& Yasakov, Y. V. (2016). Distributed database management system for integrated processing of spatial data in a gis. Computer Optics, 40(6), 919-928. doi:10.18287/2412-6179-2016-40-6-919-928

Williamson, I.P., Grant, D. and Rajabifard, A. (2005). 'Land Administration and Spatial Data Infrastructure'. Proceedings of FIG Working Week/ GSDI-8, Cairo.

Wu, X., Hong, D., Ghamisi, P., Li, W., \& Tao, R. (2018). MsRi-CCF: Multi-scale and rotation-insensitive convolutional channel features for geospatial object detection. Remote Sensing, 10(12) doi:10.3390/rs10121990

Yang, L., Jin, S., Danielson, P., Homer, C., Gass, L., Bender, S. M., . . Xian, G. (2018). A new generation of the united states national land cover database: Requirements, research priorities, design, and implementation strategies. ISPRS Journal of Photogrammetry and Remote Sensing, 146, 108-123. doi:10.1016/j.isprsjprs.2018.09.006

Yu, S. -., Shin, D. -., \& Ahn, J. -. (2016). A study on concepts and utilization of geo-spatial big data in south korea. KSCE Journal of Civil Engineering, 20(7), 2893-2901. doi:10.1007/s12205-016-0504-7 